\title{
Modeling and Forecasting of Carbon Dioxide Emissions in Bangladesh Using Autoregressive Integrated Moving Average (ARIMA) Models
}

\author{
Abdur Rahman*, Md Mahmudul Hasan \\ Department of Statistics, Shahjalal University of Science and Technology, Sylhet, Bangladesh \\ Email: *airdipu@gmail.com
}

How to cite this paper: Rahman, A. and Hasan, M.M. (2017) Modeling and Forecasting of Carbon Dioxide Emissions in Bangladesh Using Autoregressive Integrated Moving Average (ARIMA) Models. Open Journal of Statistics, 7, 560-566. https://doi.org/10.4236/ojs.2017.74038

Received: March 17, 2017

Accepted: July 25, 2017

Published: July 28, 2017

Copyright ( 92017 by authors and Scientific Research Publishing Inc. This work is licensed under the Creative Commons Attribution International License (CC BY 4.0). http://creativecommons.org/licenses/by/4.0/

\begin{abstract}
In the present paper, different Autoregressive Integrated Moving Average (ARIMA) models were developed to model the carbon dioxide emission by using time series data of forty-four years from 1972-2015. The performance of these developed models was assessed with the help of different selection measure criteria and the model having minimum value of these criteria considered as the best forecasting model. Based on findings, it has been observed that out of different ARIMA models, ARIMA $(0,2,1)$ is the best fitted model in predicting the emission of carbon dioxide in Bangladesh. Using this best fitted model, the forecasted value of carbon dioxide emission in Bangladesh, for the year 2016, 2017 and 2018 as obtained from ARIMA $(0,2,1)$ was obtained as 83.94657 Metric Tons, 89.90464 Metric Tons and 96.28557 Metric Tons respectively.
\end{abstract}

\section{Keywords}

Carbon Dioxide, Modeling, Forecasting, Time Series, ARIMA, Bangladesh

\section{Introduction}

Generally, emission of carbon dioxide $\left(\mathrm{CO}_{2}\right)$ from living animals, humans, wetlands, volcanoes, and other sources is nearly balanced by the same amount being removed from the atmosphere by plant photosynthesis and by the oceans. $\mathrm{Hu}-$ man activity is disturbing this equilibrium by generating increased $\mathrm{CO}_{2}$ from fossil fuels like as coal, gas, and petroleum products; and combustion via electricity generation, transportation, industry, and domestic use. The results of these imbalances are believed to be greenhouse effects: global warming, melting of polar ice sheets and caps, a rise in sea levels and subsequent coastal inunda- 
tions, and damage to agriculture and natural ecosystems, among others. There is an increasing trend of greenhouse gas (GHG) emissions worldwide due to human activities, which indicates a substantial increase in atmospheric concentrations of carbon dioxide $\left(\mathrm{CO}_{2}\right)$, methane $\left(\mathrm{CH}_{4}\right)$, nitrous oxide $\left(\mathrm{N}_{2} \mathrm{O}\right)$, hydrofluorocarbons (HFCs), perfluorocarbons (PFCs) and sulphur hexafluoride $\left(\mathrm{SF}_{6}\right)$ (EPA, 2014) [1]. IPCC (2007) [2] shows that carbon dioxide is the most dominant GHGs (greenhouse gases) which accounted $77 \%$ of the total global GHG emission where $\mathrm{CH}_{4}, \mathrm{~N}_{2} \mathrm{O}$ and other gases contributed $14 \%, 8 \%$ and $1 \%$ respectively.

Climate change as a result of global warming has become one of the most important issues in the recent years. Reddy et al. (1995) shows that global mean temperature will also rise to $3^{\circ} \mathrm{C}-4^{\circ} \mathrm{C}$ with doubling of the $\mathrm{CO}_{2}$ concentration [3]. In 2007, the Intergovernmental Panel on Climate Change reported that there would be an estimated rise in the average global temperature between $1.1^{\circ} \mathrm{C}$ and $6.4^{\circ} \mathrm{C}$ within the next 100 years [2]. Lau et al. (2009) shows that a meager $2^{\circ} \mathrm{C}$ increase in temperature would greatly hamper many ecosystems and would cause an increase in the sea-level that would adversely impact the lives of people living in coastal zones [4].

The developed countries have a much higher share in global emissions than the developing ones. Nakicenovic (1994) [5] studied the perspectives of GHG emission on a regional basis. He stated that the developing countries are responsible for less than $16 \%$ of the $\mathrm{CO}_{2}$ concentration due to their past consumption of fossil energy. The developed countries have a much higher share in global emissions than the developing ones. In Bangladesh, the power sector alone contributes $40 \%$ of the total $\mathrm{CO}_{2}$ emissions [6] [7]. Sarkar et al. (2015) has shown that the growth of $\mathrm{CO}_{2}$ emission found $6.7 \%$ per year which is higher than the growth of GDP and energy consumption in Bangladesh [8]. According to the third Assessment Report of IPCC (2007) [2], Bangladesh is the most vulnerable region of the world to climate change impacts [6] [9] [10] [11] [12]. Global warming has caused fundamental changes to our climate. According to the IPCC (2001) [13], a $45 \mathrm{~cm}$ sea-level rise could cause a potential land loss of $10.9 \%$ and a one meter sea-level rise a loss of $20.7 \%$. Recently, the IPCC, in its Fifth Assessment Report, has suggested a $1.5 \mathrm{~mm}$ sea-level rise per year for Bangladesh. According to the IPCC (2007) Bangladesh will loose about $8 \%$ of its rice and $32 \%$ wheat production by the year 2050. The UNDP (2007) [14] predicts that $11 \%$ of the population will be directly threatened by a one meter sea-level rise. Rahman et al. (2015) [15] shows that in Bangladesh the maximum temperature increased significantly by 0.021 degree Celsius per year in Cox's Bazar and Sylhet region which is alarming for Bangladesh.

\section{Materials}

In the present study, time series secondary data on carbon dioxide emissions in Bangladesh were considered for the period 1972 to 2015 from Boden et al. (2016), UNFCCC (2016), BP (2016) [16] [17] [18]. The time series secondary 
data were analyzed with the help of various ARIMA models and have forecast using the appropriate model which was selected using the minimum selection criteria.

\section{Methods}

ARIMA is one of the most traditional methods of non-stationary time series analysis. In contrast to the regression models, the ARIMA model allows time series to be explained by its past or lagged values and stochastic error terms. The models developed by this approach are usually called ARIMA models because they use a combination of autoregressive (AR), integration (I) - referring to the reverse process of differencing to produce the forecast and moving average (MA) operations [19].

The ARIMA model is denoted by ARIMA $(p, d, q)$, where " $p$ " stands for the order of the auto regressive process, " $d$ " is the order of the data stationary and " $q$ " is the order of the moving average process. The general form of the ARIMA $(p, d, q)$ can be written as [20],

$$
\Delta^{d} y_{t}=\delta+\theta_{1} \Delta^{d} y_{t-1}+\theta_{2} \Delta^{d} y_{t-2}+\cdots+\theta_{p} y_{t-p}+e_{t-1} \alpha e_{t-1}-\alpha_{2} e_{t-2} \alpha_{q} e_{t-2}
$$

where, $\Delta^{d}$ denotes differencing of order $d$, i.e., $\Delta y_{t}=y_{t}-y_{t-1}, \Delta^{2} y_{t}=\Delta y_{t}-\Delta y_{t-1}$ and so forth, $y_{t-1}, \cdots, y_{t-p}$ are past observations (lags), $\delta, \theta_{1}, \cdots, \theta_{p}$ are parameters (constant and coefficient) to be estimated similar to regression coefficients of the Auto Regressive process (AR) of order " $p$ ” denoted by AR $(p)$ and is written as,

$$
Y=\delta+\theta_{1} y_{t-1}+\theta_{2} y_{t-2}+\cdots+\theta_{p} y_{t-p}+e_{t}
$$

where, $e_{t}$ is forecast error, assumed to be independently distributed across time with mean $\theta$ and variance $\theta_{2} e, e_{t-1}, e_{t-2}, \cdots, e_{t-q}$ are past forecast errors, $\alpha_{1}, \cdots, \alpha_{q}$ are moving average (MA) coefficient. While MA model of order $q$ (i.e.) MA $(q)$ can be written as,

$$
Y_{t}=e_{t}-\alpha_{1} \alpha_{t-1}-\alpha_{2} e_{t-2}-\cdots-\alpha_{q} e_{t-q}
$$

Seasonal ARIMA model is to denoted by ARIMA $(p, d, q)(\mathrm{P}, \mathrm{D}, \mathrm{Q})$, where $\mathrm{P}$ denotes the number of seasonal autoregressive components, $Q$ denotes the number of seasonal moving average terms and $\mathrm{D}$ denotes the number of seasonal differences required to induce stationarity [21]. The steps which are followed in order to define an ARIMA model as stated by Box \& Jenkins:

a) Identifying a model;

b) Estimating the parameters of the model;

c) Diagnostic checking.

In the present paper, time series yearly data on emissions of carbon dioxide in Bangladesh were considered so there is no seasonal variation in the data which means non-seasonal ARIMA $(p, d, q)$ models are applicable only. Comparison among family of different parametric combination of ARIMA $(p, d, q)$ was done on the basis of minimum value of selection criteria which are Root mean 
squared error (RMSE), Mean percentage error (MPE), Mean absolute percentage error (MAPE), Mean absolute error (MAE), Maximum absolute percentage error (MAPE), Maximum absolute standard error (MASE) and Bayesian information criteria (BIC) [22] [23].

\section{Result and Discussion}

In Figure 1, from the autocorrelation (ACF) and partial autocorrelation (PACF), it is clear that there is no significant spike in the original series which also indicates that there are no significant effects of Auto-Regressive and Moving Average in the original series, that is, the carbon dioxide emission series is stationary without any difference.

After making the series stationary, different parametric combinations of ARIMA $(p, d, q)$ model were tried to analyze the forty-four-year data (1972 to 2015) of carbon dioxide emission and the best fitted model is accepted on the basis of minimum value of all selection criteria as mentioned above in methodology. The results of performance of developed ARIMA $(p, d, q)$ model is presented in Table 1. Table 1 exposed the performance of twenty ARIMA Models out of which ARIMA $(0,2,1)$ was best out of all. ARIMA $(0,2,2)$ and ARIMA $(1,2,1)$ ranks second and third respectively while remaining ARIMA Models are not as good as these three.

Therefore, it was concluded that the appropriate model for forecasting the carbon dioxide emission in Bangladesh during 2015 was ARIMA $(0,2,1)$ having minimum value of all selection criteria as compared to remaining nineteen models.

Table 2 shows the forecasted value of carbon dioxide emission using the best fitted model ARIMA $(0,2,1)$. The forecasted value of carbon dioxide emission in Bangladesh, for the year 2016, 2017 and 2018 as obtained from

ARIMA $(0,2,1)$ was obtained as 83.94657 Metric Tons, 89.90464 Metric Tons and 96.28557 Metric Tons with Upper emission limit (UEL) and Lower emission limit (LEL) are 92.21431 Metric Tons and 75.96045 Metric Tons, 98.72545 Metric Tons and 81.13923 Metric Tons, 105.90164 Metric Tons and 87.02782 Metric Tons respectively.
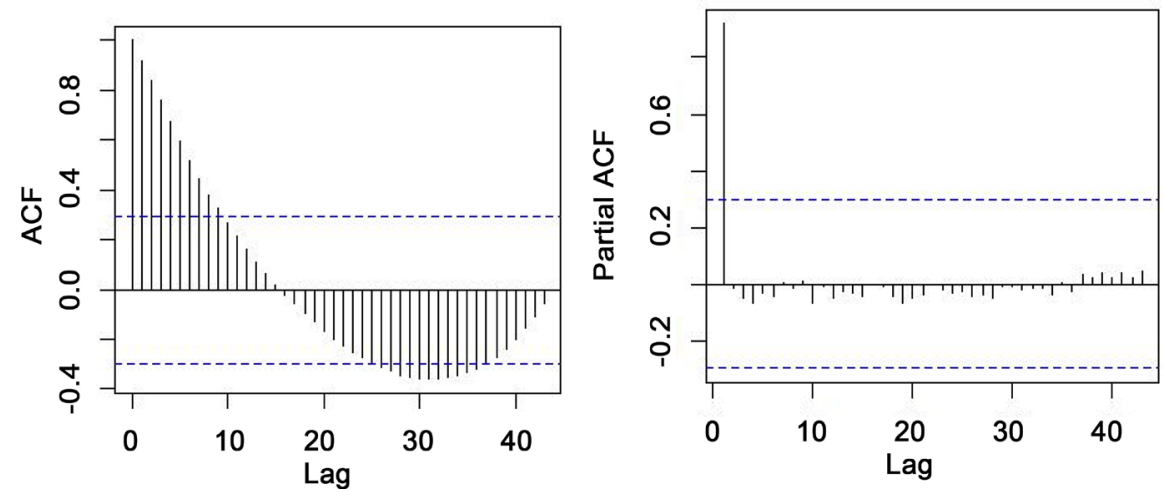

Figure 1. Autocorrelation and Partial Autocorrelation graph. 
Table 1. Performances of different ARIMA $(p, d, q)$ models of carbon dioxide in Bangladesh.

\begin{tabular}{|c|c|c|c|c|c|c|c|}
\hline \multirow{2}{*}{ Models } & \multicolumn{7}{|c|}{ Model Selection Criteria } \\
\hline & RMSE & MAE & MPE & MAPE & MASE & AIC & BIC \\
\hline $\operatorname{ARIMA}(0,1,0)$ & 2.3425 & 1.7402 & 6.6104 & 7.1229 & 0.9773 & 198.22 & 199.98 \\
\hline $\operatorname{ARIMA}(0,1,1)$ & 1.9891 & 1.4639 & 4.7313 & 6.5207 & 0.8221 & 186.35 & 189.88 \\
\hline $\operatorname{ARIMA}(0,1,2)$ & 1.5460 & 1.1544 & 3.1398 & 5.6675 & 0.6483 & 168.01 & 173.29 \\
\hline ARIMA $(0,1,3)$ & 1.4824 & 1.1296 & 2.5420 & 5.6682 & 0.6344 & 166.91 & 173.96 \\
\hline $\operatorname{ARIMA}(1,1,0)$ & 1.5956 & 1.2749 & 1.8421 & 6.2357 & 0.7159 & 168.03 & 171.55 \\
\hline $\operatorname{ARIMA}(1,1,2)$ & 1.4660 & 1.14591 & 2.1419 & 5.8150 & 0.6435 & 165.74 & 171.55 \\
\hline $\operatorname{ARIMA}(2,1,0)$ & 1.4060 & 1.1035 & 1.1014 & 5.4728 & 0.6197 & 159.71 & 164.99 \\
\hline $\operatorname{ARIMA}(2,1,1)$ & 1.4021 & 1.1024 & 1.1528 & 5.5165 & 0.6191 & 161.5 & 168.55 \\
\hline ARIMA $(2,1,2)$ & 1.3333 & 0.9679 & 1.0146 & 4.8551 & 0.5436 & 159.86 & 168.67 \\
\hline $\operatorname{ARIMA}(2,1,3)$ & 1.2603 & 0.9817 & 0.8985 & 5.1329 & 0.5513 & 157.32 & 167.88 \\
\hline $\operatorname{ARIMA}(0,2,0)$ & 1.6744 & 1.3174 & -0.0317 & 6.3415 & 0.7398 & 166.44 & 168.18 \\
\hline $\operatorname{ARIMA}(0,2,1)$ & 1.3216 & 0.9600 & 0.4590 & 4.6932 & 0.5391 & 149.42 & 152.9 \\
\hline $\operatorname{ARIMA}(0,2,2)$ & 1.3212 & 0.9558 & 0.4602 & 4.6698 & 0.5368 & 151.41 & 156.62 \\
\hline $\operatorname{ARIMA}(0,2,3)$ & 1.2666 & 1.0051 & 0.3100 & 5.1614 & 0.5644 & 150.1 & 157.05 \\
\hline $\operatorname{ARIMA}(1,2,0)$ & 1.4139 & 1.1248 & 0.0158 & 5.4194 & 0.6317 & 154.57 & 158.05 \\
\hline $\operatorname{ARIMA}(1,2,1)$ & 1.3211 & 0.9547 & 0.4604 & 4.6638 & 0.5361 & 151.41 & 156.62 \\
\hline ARIMA $(1,2,2)$ & 1.3079 & 0.9478 & 0.4499 & 4.5701 & 0.5323 & 152.59 & 159.54 \\
\hline $\operatorname{ARIMA}(1,2,3)$ & 1.2481 & 0.9741 & 0.3619 & 4.9698 & 0.5470 & 150.78 & 159.47 \\
\hline $\operatorname{ARIMA}(2,2,1)$ & 1.3140 & 0.9719 & 0.4336 & 4.7371 & 0.5458 & 152.9 & 159.85 \\
\hline $\operatorname{ARIMA}(2,2,3)$ & 1.1497 & 0.9081 & 0.3649 & 4.6018 & 0.5101 & 149.43 & 159.85 \\
\hline
\end{tabular}

Table 2. Forecast of carbon dioxide emission in Bangladesh using ARIMA $(0,2,1)$ during 2016 to 2018.

\begin{tabular}{cccc}
\hline Year & Forecast & LEL $^{*}$ & UEL* $^{*}$ \\
\hline 2016 & 83.94657 & 75.96045 & 92.21432 \\
2017 & 89.90464 & 81.13923 & 98.72545 \\
2018 & 96.28557 & 87.02782 & 105.90164 \\
\hline
\end{tabular}

${ }^{*} 95 \%$ confidence interval.

\section{Conclusion}

This paper aimed to model the emission of carbon dioxide during 2015 in Bangladesh, by Autoregressive Integrated Moving Average (ARIMA) approach. On basis of results obtained, it is concluded that $\operatorname{ARIMA}(0,2,1)$ model having minimum value of all measures of selection criteria was found to be the appropriate model amongst all for predicting the carbon dioxide emission in Bangladesh. The model showed a good performance in case of explaining variability in 
the data series and, it's predicting ability. Using the model ARIMA $(0,2,1)$ we obtained the emission as 83.94657 Metric Tons, 89.90464 Metric Tons and 96.28557 Metric Tons in the year 2016, 2017 and 2018. However, the forecasting of carbon dioxide can help the government of Bangladesh and world leaders as well as the policy makers for taking the appropriate plan for reducing the future emission of carbon dioxide in Bangladesh.

\section{Acknowledgements}

We would like to acknowledge Md. Ahmed Kabir Chowdhury, Professor, Department of Statistics, Shahjalal University of Science \& Technology, Sylhet, Bangladesh.

\section{Conflicts of Interest}

The authors declare no conflict of interest.

\section{References}

[1] EPA (2014) Climate Change Indicators in the United States: Global Greenhouse Gas Emissions. www.epa.gov/climatechange/indicators

[2] IPCC (2007) Climate Change 2007: Impacts, Adaptation and Vulnerability. In: Parry, M.L., Canziani, O.F., Palutikof, J.P., van der Linden, P.J. and Hanson, C.E., Eds., Contribution of Working Group II to the Fourth Assessment Report of the Intergovernmental Panel on Climate Change, Cambridge University Press, Cambridge, 976.

[3] Reddy, V.R., Reddy, K.R. and Acock, B. (1995) Carbondioxide and Temperature Interactions on Stem Extension, Node Initiation and Fruiting in Cotton. Agriculture, Ecosystems \& Environment, 55, 17-28. https://doi.org/10.1016/0167-8809(95)00606-S

[4] Lau, L.C., Tan, K.T., Lee, K.T. and Mohamed, A.R. (2009) A Comparative Study of the Energy Policies in Japan and Malaysia in Fulfilling Their Nations Obligations towards the Kyoto Protocol. Energy Policy, 37, 4771-4780. https://doi.org/10.1016/j.enpol.2009.06.034

[5] Nebojsa, N. (1994) Energy Strategies for Mitigating Global Change. Technology Responses to Global Environmental Challenges, OECD/IEA, Paris, 449-459.

[6] ADB (1994) Climate Change in Asia: Bangladesh Country Report, Regional Study on Global Environmental Issues, Asian Development Bank, Regional Study on Global Environmental Issues Series, Manila, The Philippines.

[7] Shrestha, R.M., Anandarajah, G. and Liyanage, M.H. (2009) Factors Affecting $\mathrm{CO}_{2}$ Emission from the Power Sector of Selected Countries in Asia and the Pacific. Energy Policy, 37, 2375-2384. https://doi.org/10.1016/j.enpol.2009.01.032

[8] Sarkar, M.S.K., Sadeka, S., et al. (2015) Energy Consumption and $\mathrm{CO}_{2}$ Emission in Bangladesh: Trends and Policy Implications. Asia Pacific Journal of Energy and Environment, 2, 175-182.

[9] McCarthy, J.J., Canziani, O.F., Leary, N.A., Dokken, D.J. and White, K.S. (2001) Climate Change 2001: Impacts, Adaptation and Vulnerability, Inter-Governmental Panel on Climate Change (IPCC), Work Group II Input to the Third Assessment Report, Cambridge University Press, Cambridge. 
[10] Ali, A. (1996) Vulnerability of Bangladesh to Climate Change and Sea Level Rise through Tropical Cyclones and Storm Surges. Journal of Water Air Soil Pollution, 92, 171-179. https://doi.org/10.1007/978-94-017-1053-4_16

[11] Ali, A. (1999) Climate Change Impacts and Adaptation Assessment in Bangladesh. Climate Research, 12, 109-116. https://doi.org/10.3354/cr012109

[12] Piguet, E. (2008) Climate Change and Forced Migration. Research Paper No. 153. UNHCR, Evaluation and Policy Analysis Unit, Geneva.

[13] IPCC (2001) Science of Climate Change-Third Assessment Report (AR3) of the Intergovernmental Panel on Climate Change, Cambridge University Press, Cambridge.

[14] UNDP (2007) Human Development Report 2007/2008, Fighting Climate Change: Human Solidarity in a Divided World. UNDP, New York.

[15] Rahman, A., Haque Jiban, M. and Munna, S. (2015) Regional Variation of Temperature and Rainfall in Bangladesh: Estimation of Trend. Open Journal of Statistics, 5, 652-657. https://doi.org/10.4236/ojs.2015.57066

[16] Boden, T.A., Marland, G. and Andres, R.J. (2016) Global, Regional, and National Fossil-Fuel $\mathrm{CO}_{2}$ Emissions, Carbon Dioxide Information Analysis Center, Oak Ridge National Laboratory, U.S. Department of Energy, Oak Ridge, Tennessee.

[17] UNFCCC (2016) National Inventory Submissions 2016. United Nations Framework Convention on Climate Change.

http://unfccc.int/national_reports/annex_i_ghg_inventories/national_inventories_s ubmissions/items/9492.php

[18] BP (2016) Statistical Review of World Energy. http://www.bp.com/en/global/corporate/energy-economics.html

[19] Box, G.E.P. and Jenkins, G.M. (1970) Time Series Analysis: Forecasting and Control. Holden-Day, San Francisco.

[20] Judge, G.G., Carter Hill, R., William, E.G. and Helmut, I. (1988) Introduction to the Theory and Practice of Econometrics. 2nd Edition, John Wiley and Son, New York.

[21] Box, G.E.P., Jenkins, G.M. and Reinsel, G.C. (1994) Time Series Analysis, Forecasting and Control. 3rd Edition, Prentice Hall, Englewood Cliffs, New Jersey.

[22] Kumari, P., Mishra, G.C., Pant, A.K., Shukla, G. and Kujur, S.N. (2014) Autoregressive Integrated Moving Average (ARIMA) Approach for Prediction of Rice (Oryza Sativa 1.) Yield in India. The Bioscan-An International Quarterly Journal of Life Science, 9, 1063-1066.

[23] Rahman, F.N.M., Rahman, M.M. and Baten, M.A. (2013) Modeling for Growth and Forecasting of Pulse Production in Bangladesh. Research Journal of Applied Sciences, Engineering and Technology, 5, 5578-5587. 
Submit or recommend next manuscript to SCIRP and we will provide best service for you:

Accepting pre-submission inquiries through Email, Facebook, LinkedIn, Twitter, etc. A wide selection of journals (inclusive of 9 subjects, more than 200 journals)

Providing 24-hour high-quality service

User-friendly online submission system

Fair and swift peer-review system

Efficient typesetting and proofreading procedure

Display of the result of downloads and visits, as well as the number of cited articles Maximum dissemination of your research work

Submit your manuscript at: http://papersubmission.scirp.org/

Or contact ojs@scirp.org 